\title{
MUSEO, NOVELA, ARCHIVO. APROXIMACIÓN A LOS MUSEOS DE PAPEL*
}

\author{
MUSEUM, NOVEL, ARCHIVE. APPROACH TO PAPER MUSEUMS
}

\section{JUAN D. CID HIDALGO**}

\section{RESUMEN}

Por medio de este trabajo pretendemos reparar sobre cierta sensibilidad museal presente en un buen número de novelas latinoamericanas del siglo XX. La posibilidad del diálogo entre literatura e imagen museo nos motiva a leer en conjunto estas dos "experiencias" que en la tradición europea, fundamentalmente francesa, ha tenido un desarrollo especialmente interesante desde el realismo y el naturalismo. Pensar el museo desde la literatura nos permite, entonces, relativizar los criterios de autoridad de aquellas instituciones que se han instalado como organismos republicanos sostenedores de un proyecto de nación, como la gran institución del quehacer cultural, a la vez que comprender la noción de archivo como constructora de memoria, la cual se inscribe en bloques curatoriados y montados por medio del acto de narrar.

Palabras clave: Museo, novela, memoria, archivo, poder, arte.

\section{ABSTRACT}

In this work we intend to observe certain museum dimension among a good number of Latin American novels from the 20th century. The possibility of dialogue between literature and museum image motivates us to read these two "experiences" together that, in European tradition and the French one in particular, have had an especially

* Este trabajo forma parte de una investigación mayor denominada "Apuntes sobre la dimensión museal de la literatura latinoamericana o los museos de papel” (Proyecto FONDECYT No 11121221).

** Dr. en Literatura Latinoamericana. Profesor del Departamento de Español, Facultad de Humanidades y Arte, Universidad de Concepción. Concepción, Chile. Correo electrónico: jdcid@ udec.cl 
interesting development from realism naturalism. To see the museum from the point of view of literature allows us, then, to play down the criteria of authority of those institutions that have been set up as republican organisations sustaining a nation project, such as the great institution of cultural task. It also allow us to comprehend the notion of archive as memory constructor which is, therefore, built with blocks of curatorship archives and assembled by story telling.

Keywords: Museum, novel, memory, archive, power, art.

Recibido: 30.03 .15 . Aceptado: 12.09.15.

"Las artes plásticas han inventado su imprenta".

H. Malraux

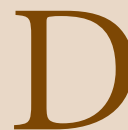

ESDE LA DEFINICIÓN dada a "museo" en 1765 por Louis de Jancourt (el autor más prolífico de la Encyclopédie de Diderot con cerca de 17.000 artículos) hasta la definición del organismo internacional rector del universo museológico el ICOM (International Council of Museum) consagrada en 1971, han transcurrido más de doscientos años. Tiempo que testimonia el paso de una concepción basada en el espíritu de coleccionista (archivista dirán Foucault y González Echevarría) que, tras la Revolución Francesa, se convierte en un dispositivo de protección del patrimonio inmueble, de investigación y sobre todo en un instrumento didáctico. Definiciones que por cierto escamotean un problema de alcances mayores y cuyo desafío motiva esta investigación ${ }^{1}$.

Al comenzar vale la pena realizar una constatación de base. La influencia decisiva del museo en el desarrollo de las artes visuales o plásticas ha desbordado este territorio para instalarse en múltiples y heterogéneos espacios culturales (Huyssen, 1996). De este modo el museo, el mismo definido por cualidades inmovilizadoras que privilegian el hermetismo y el mismo que autoriza el paso de ciertos productos culturales al mausoleo sacralizado, ahora se refunda como eje de innumerables actividades culturales contemporáneas y como material de trabajo de la literatura.

El destacado intelectual mexicano Alfonso Reyes, en la década del 20 del siglo pasado, ya había puesto el acento en la desarticulación de esta

\footnotetext{
${ }^{1}$ Para mayores antecedentes creemos valioso el trabajo "La macchina del museo si presta straordinariamente all'organizzazione del nuovo sopere borghese" de Binni y Pinna en Museo. Storia e funzioni di una macchina culturale dal cinquecento a oggi, profilo storico, elementi di museologia, documenti, bibliografie (1989).
} 
imagen arquitectónica cuando propone -en "Contra el museo estático" (1924)- dinamizar el mausoleo, rompiendo la verticalidad de las relaciones propuestas por ese organismo cultural de modo que incluso las miradas de los visitantes o espectadores de las exhibiciones pudieran convertirse en un motivo plástico y, por lo tanto, exponible en ese recinto memorial. La posibilidad de esta subjetividad radical la sugiere con una imagen plásticopoética perturbadora:

quemar los museos y fundar el museo dinámico, el cine de culto, el film de tres dimensiones, donde el bordador chino borde tapices chinos, y donde el espectador pueda, si le place, ser también personaje y realizar sus múltiples capacidades de existencia... Queremos el museo-teatrocirco, con derecho a saltar al plano de las ejecuciones (Reyes, 1924, p. 47).

De este modo Reyes sugiere desembarazarse de los objetos, cuestión relevante cuando comprendemos que el ejercicio museal en su origen revela una profunda obsesión por ellos y el anhelo de posesión casi incontrola$b^{2}$. Orhan Pamuk describe bellamente lo expuesto cuando apunta en el capítulo 64, "Incendio en el bósforo", de El museo de la inocencia (2008) que la obsesión por los objetos es un indicador de la imposibilidad de poseer aquello que se desea. En el acto de coleccionar se logra rozar el fuego del placer por la posesión (458 y ss). Al respecto, entonces, las distintas perspectivas narrativas ofrecidas por algunas novelas latinoamericanas van develando aquella "herencia agobiadora" percibida por Marta Traba en $E l$ museo vacío (1958), donde el desconcierto y la perplejidad desestabilizan la aparente sencillez de la aventura que significa deambular por los sacralizados pasillos de una de las construcciones sustentadoras de la idea de nación, de memoria (sancionadora de aquello relevante para la cultura), para una ideología, para los poderes. El trabajo curatorial (selección, conservación, puesta en valor y montaje de archivos) al que es sometido la

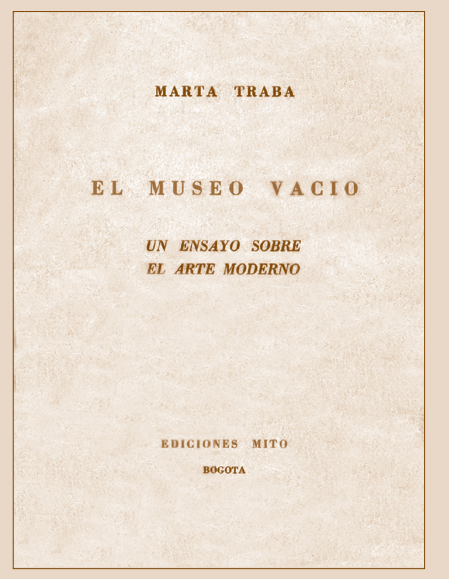

${ }^{2}$ Philipp Blom en El coleccionista apasionado. Una historia intima (2013) describe algunos alcances de esta actividad: "Durante toda la Edad Media, los príncipes de la Iglesia y los gobernantes laicos acumularon montones de reliquias, recipientes lujosos, joyas y objetos tales como cuernos de unicornio y otras criaturas legendarias. A partir de dichos tesoros se desarrolló, desde el siglo XIV, una modalidad privada de apreciación del coleccionismo, el studiolo, una habitación construida ad hoc y repleta de antigüedades, piedras preciosas y esculturas, popular en Italia entre hombres con recursos y cultura. Se cree que Oliviero Forza, de Treviso, tuvo, en 1335, el primer studiolo del que se conservan datos. Coleccionar obras de arte y objetos diseñados con metales y piedras preciosas pasó a ser un pasatiempo principesco, una diversión que podía llegar a confundirse con una pasión devoradora" (2013, p. 30). 

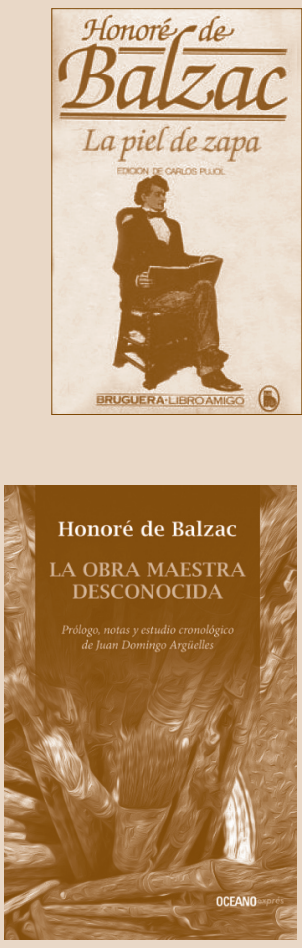

memoria pareciera ser uno de los elementos de importancia en que novela y museo se emparentan, fundamentalmente por su empleo de aquello que Roberto González Echevarría ha denominado "ficciones del archivo" (2000), materializaciones narrativas que denotan la obsesión textual de la literatura latinoamericana por el archivo, ficciones que "siguen buscando la clave de la cultura y la identidad latinoamericana" (González, 2000, p. 238). Así como el museo conjura el olvido, la novela o el carácter memorial de los textos otorgan al museo de papel (literario) un rol singular en que las artes se justifican como instancias de salud (Deleuze, 1996), con lo cual el ejercicio curatorial se transforma en una actividad constructora de ese pueblo que falta.

La posibilidad de diálogo entre literatura y museo nos motiva a leer en conjunto estas dos "experiencias" que en la tradición europea, fundamentalmente francesa, ha tenido un desarrollo especialmente interesante desde el realismo y el naturalismo. Balzac con La piel de zapa y en La obra maestra desconocida (ambas de 1831) realiza una descripción detallada del interior de las casas burguesas vistas como museos en cuanto hacen acopio de las singulares relaciones entre el hombre europeo y los objetos, sus colecciones y, por supuesto, sus exhibiciones. Cómo olvidar la ironía de $L a$ taberna (1877) de Emile Zola (texto muy conocido entre los investigadores de la museología) en que se nos narra el peregrinar de un grupo de invitados a una boda perdidos en el Museo del Louvre, escena que privilegia la acepción del museo como almacén o bodega en que las obras descontextualizadas (o sobresignificadas al momento de su inclusión en el edificio de las bellas artes) pierden su valor debido a esa falsa solemnidad atribuida a obras que en ese territorio han domesticado el placer de su belleza: "las ideas de clasificación, de conservación y de utilidad pública... tienen poco que ver con los placeres" (1999, p. 137) dirá Paul Valery en Piezas sobre arte. El estudio sistemático de las relaciones entre las distintas artes, entonces, no es importante solamente por el conocimiento multifocal de nuestra tradición cultural, sino por la capacidad de observación, comprensión y análisis, a partir de una perspectiva integradora, que posibilita un proceso creador de sentidos, de un relato memorial, en muchos casos, en franca polémica con el poder normalizador. En adelante el lector/espectador será consciente de la capacidad correpetidora de las artes y, lo que es mejor, de su capacidad de explorar zonas de sentido que construyan el porvenir.

El museo, al igual que otras múltiples zonas ciudadanas, se mueve entre tiempo real y velocidad (Virilio, 1997), entrelugar que ha ido desestabilizando este espacio memorial (Nora, 2009) tan relevante en la cultura mo- 
derna y tan complejo en sus alcances prácticos y simbólicos ${ }^{3}$. La tendencia, en este contexto, es lo que Virilio ha llamado la desaparición, es decir, la estética del museo de cierto modo adviene estética de la desaparición (1997), de la borradura que en ese ejercicio de fuerza precisamente hace aparecer lo borrado, aquello que resiste el olvido, aquello cuya memoria permanece, insistente como la vida, como el arte, como la literatura. Aunque "el papel del museo como lugar de conservación elitista, bastión de la tradición y la alta cultura, dio paso al museo como medio de masas, como marco de la miseen-scene espectacular y la exuberancia operática" (Huyssen, 1996, p. 16) el componente humano, aquel resistente y aglutinador del principio esperanza, permanece liberado en un descontrol gozoso y plural.

La finalidad de esta investigación es desarrollar precisamente esa área en que productos culturales como la literatura (novela, cuento) y la plástica configuran una arremetida sobre problemas de orden estético, teórico y, por supuesto, prácticos en que la imagen simbólica del museo abre caminos posibles para desarticular algunas certezas, percibir la configuración de la memoria (Maleuvre, 1999), ya sea personal o colectiva, y cómo en él se reproduce la paradoja de la seducción por el objeto y el rechazo del mismo, donde lo coleccionado bajo ciertos criterios de interés y, por lo tanto, consagrados como eminentes por el poder, luego se transforman en objetos que sacuden y resisten al poder que los consagró. En el ejercicio de fuerza que significa escoger y eliminar archivos (Derrida, 2001) se va curatoriando, entonces, un relato interesado al provenir, un relato que privilegia las discontinuidades y la crítica al poder que insiste en homogeneizar y clausurar la disidencia.

Henry Malraux en su Museo imaginario (1956) será categórico al declarar que "el museo suple defectos de nuestra memoria" (Malraux, 1956, p. 14), por lo tanto el rol institucional del museo en la definición de un concepto de nación es apreciable y lo ubica dentro de los dispositivos de vigilancia del orden y punición social. En la afamada novela de Adolfo Bioy Casares La invención de Morel (1940) el museo funciona como panóptico, desde donde se vigila insistentemente a los turistas y desde donde se coleccionan y archivan las escenas repetidas de hombres y mujeres en un simu-

\footnotetext{
${ }^{3}$ Aurora León en El museo. Teoría, praxis y utopía (2010) señala una condición de base en la aparición del museo como lógica superación del espíritu del coleccionista: "El museo nace de una grave contradicción: su razón de ser fundamental ("conservar" las obras, la mayoría procedentes de colecciones privadas) niega la actual visión del museo, como centro "abierto" y público. En este sentido, se impone una revitalización de los fondos del museo, poner al día las obras del pasado que han de ser utilizadas en el presente. Además, el museo es paradójica y diametralmente opuesto al arte" (2010, pp. 67-70).
}

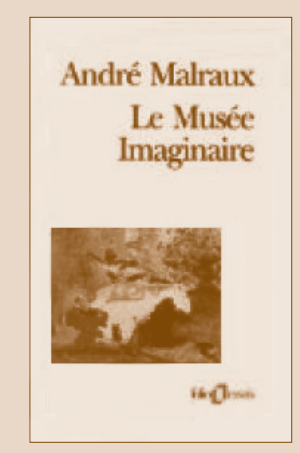


lacro interminable, donde lo único imperecedero son las grabaciones de la máquina que registra y encierra aquello significativo en la pinacoteca, en lo alto de una colina, en el museo. Por otro lado, Américo Castilla en "El museo como construcción política"4 agrega que "en sus colecciones se encuentran las evidencias materiales de todos los enunciados que componen el cuerpo de la cultura, sus indicios y sus marcas" (2010, p. 17), ambas proposiciones en el contexto planteado abren una discusión apasionante que dice relación -ahora con Foucault- con que aquello resguardado y prestigiado como valioso es material primero y último de una construcción discursiva particular - parte de un proyecto mayor, en algunos casos ideológico, en otros político y en otros utópico- marcada por las estructuras de poder que orientan o inducen ciertas interpretaciones acomodaticias de los posibles significados de las obras coleccionadas e inmovilizadas en sus pinacotecas; por lo tanto, la labor curatorial pareciera la continuación de una actividad política por otros medios. De ahí entonces que reconocemos cierta afinidad entre las proposiciones de Michel Foucault y Roberto González Echevarría, para quienes la noción de archivo se circunscribe al campo de los enunciados. El francés, en Arqueología del saber, dirá: "El archivo es ante todo la ley de lo que puede ser dicho, el sistema que rige la aparición de los enunciados como acontecimientos singulares" (Foucault, 2000, p. 170). El cubano agrega: "El archivo salvaguarda, retiene, ordena su diseminación, la dicta y organiza sus regularidades como discurso. El archivo guarda el arcano, el secreto" (González, 2000, p. 66). La lectura de una parte importante de textos que hacen suya la preocupación plástica en general y su materialización más concreta -el museo-, creemos, ilumina zonas no atendidas suficientemente en la exégesis tradicional de los cuentos y novelas que adoptan el museo como material ${ }^{5}$.

${ }^{4}$ Para mayores antecedentes recomendamos la lectura de "Las políticas del museo" y "El Louvre, el olvido de la división”, capítulos claves de Catástrofe y olvido. Las ruinas, Europa, el museo de Jean Louis Déotte (1998).

${ }^{5}$ Algunas de las novelas del continente que conforman una colección de museos de papel son: El museo de la novela de la eterna (1967) de Macedonio Fernández; La lección de pintura (1979) de Adolfo Couve; Un novelista en el Museo del Prado (1984) de Manuel Mujica Lainez; Los museos abandonados (1968) y El museo de los esfuerzos inútiles (1983) de Cristina Peri Rossi; El museo de cera (1981) de Jorge Edwards; El museo de la revolución (2006) de Martín Kohan; Una novelista en el Museo del Louvre (2009) de Zoé Valdés; De sobremesa (1887-1896) del colombiano José Asunción Silva; La invención de Morel (1940) de Adolfo Bioy Casares; La región más transparente (1958) de Carlos Fuentes; Naturaleza muerta con cachimba (1990) de José Donoso; La ciudad ausente (1992) de Ricardo Piglia; El museo de lo inútil (2007) de Rodrigo Parra Sandoval; Proyecto Piel (2009) de Julio César Londoño; Leonora (2011) de Elena Poniatovska; La historia de mis dientes (2013) de Valeria Luiselli. 


\section{¿Y LA NOVELA?}

"Como el archivo, la novela atesora saber" (González, 2000, p. 62) destaca González Echevarría en Mito y archivo, idea que instala el ejercicio curatorial en un lugar de enorme expectación porque se transforma en una práctica autoritaria de la memoria, que no puede sino ser provocadora. Jacques Derrida en "El cine y sus fantasmas" (2001) anota que "El archivo es una violenta iniciativa de autoridad, de poder, es una toma de poder para el porvenir, pre-ocupa el porvenir; confisca el pasado, el presente y el porvenir. Sabemos muy bien que no hay archivos inocentes" (p. 20). El coleccionismo, referente inmediatamente anterior al museo, desde siempre ha estado relacionado con el poder tanto económico como ideológico 6 ."La archivación produce, tanto como registra, el acontecimiento” (p. 24) acotará Derrida en Mal de archivo (1997). Las colecciones, entonces, exponen, además de los objetos eminentes, representativos y cuya dignidad amerite su vigencia y recuerdo en el futuro, la violencia en la conformación del corpus donde es posible percatarse de la posición de los objetos como dispositivos de valor(es) definidos por beldades más allá de su materialidad, relegada a posiciones inferiores a favor de la consagración de la esfera simbólica que facilita su instrumentalización en direcciones tan múltiples como contradictorias. Wolfgang Ernst en Das rumoren der archiv (2002, El ruido de los archivos) apunta lúcidamente que el archivo oscila entre un "cementerio de hechos y un jardín de ficciones" (2002, p. 60).

El hospital, la prisión, el manicomio son algunos ejemplos de dispositivos de vigilancia, lista a la que agregamos el museo, construcción que reúne, encapsula y encierra contenidos (obras, objetos rupestres, arqueológicos, científicos, etc. $)^{7}$ como lo hacen las prisiones o el manicomio con

\footnotetext{
${ }^{6}$ Aurora León en el capítulo I, "Historia del coleccionismo y de los museos. Un objeto para el sujeto, un sujeto para el objeto", de El museo. Teoría, praxis y utopía, refrenda lo señalado cuando apunta: "Francia es el país que mejor ofrece el concepto de coleccionismo como expresión de la autoridad real, del absolutismo de Richelieu, de la política de Mazarino y de Colbert. Todos ellos favorecieron la formación de un gusto único (cortesano), eminentemente clasicista. Desde ahora y hasta la Revolución quedaban sentadas las bases del nuevo coleccionismo, considerado fundamentalmente como instrumento 'visual' de la ideología monárquica. Todas las monarquías (y ello es aplicable a todas las realezas europeas en proporción con la potencia económica de los fondos de la Corona) verán en el coleccionismo una forma sutil e inteligente de afianzamiento del prestigio dinástico, una expresión de alto nivel social y enriquecimiento del patrimonio que, consecuentemente, acarreará a la obra de arte una trasformación en valor ideológico y político" (2010, pp. 32-33).

${ }^{7}$ Blanchot en "El museo, el arte y el tiempo", texto recogido en La risa de los dioses, pasa revista a las opiniones de Malraux, a la sazón ministro de Cultura francés, a la discusión de sobre el arte y
} 


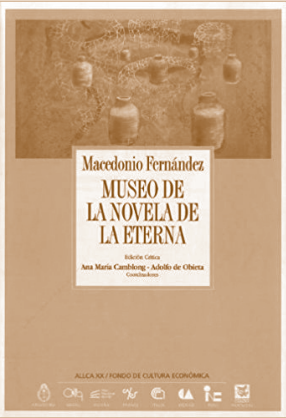

aquello que curiosamente atenta contra la estructura dominante. González Echevarría parece concordar con esto cuando en las líneas finales de su influyente texto señala: "El archivo no es un carnaval bajtiano, pero, si acaso lo es, ocurre dentro de los muros de la prisión de Foucault" (González, 2000 , p. 252). En este sentido nos parece sumamente sugestivo plantearnos cómo funciona esta dimensión en los textos, en que también hemos realizado un proceso de selección interesado precisamente para desenmascarar esta acción de que nos hacemos parte en las novelas y cuentos escogidos.

A continuación ofrecemos una mirada centrada en la incorporación de esta imagen arquitectónica y simbólica en el registro novelar y cómo se revela y descubre ante nosotros como una estructura carcelaria que, por cierto, no trabaja con cuerpos a los cuales disciplinar, pero sí con productos culturales de orden simbólico e intelectual, en muchos casos peligrosos para la estabilidad de lo social y, por lo tanto, críticos de su desempeño ${ }^{8}$.

Pasemos brevemente a visitar alguno de los museos de papel para percibir su (in)adecuación al espacio literario.

La estructura de collage plástico en El Museo de la novela de la eterna (1967) de Macedonio Fernández posibilita al lector/espectador (re) construir un relato nuevo con los retazos y las ruinas del lenguaje, con lo cual desestabiliza y dinamiza la categoría "museo" como espacio acabado, suspendido y cerrado para, verbi gracia de la escritura tartamuda, incluso fragmentaria, profundamente heterogénea y descentrada, configurar una curatoría abierta que privilegia la libertad absoluta desestabilizadora de los principios fundantes de uno y otro espacio (museal, literario). El uso de esta imagen simbólica desacralizada prueba que los dogmatismos son impracticables y que las preconcepciones, las causalidades y jerarquías ahora se van distribuyendo libremente, conformando fragmentos de un discurso no representativo sino productivo (53 prólogos). La novela de Macedonio, entonces, invita a ser leída desde la producción (Deleuze, 1996), desde

el museo a propósito de algunas declaraciones de Paul Valery: "Del mismo modo que no aceptaba con gusto la historia, no amaba los museos [...] donde veía soledades encerradas que participan de la naturaleza del templo y del salón, la escuela y el cementerio" (1976, p. 19).

${ }^{8}$ Jacques Aumont en La estética de hoy añade a propósito de las instituciones del arte que al "todo termina en la Sorbona", de Valery, sería fácil responder en eco que "todo termina en el museo", no sólo en el sentido en que el arte de vanguardia termina siempre por ser arte consagrado, sino también porque el museo parece haberse dotado de una capacidad de absorción verdaderamente digna de una ameba" (2001, p. 287). Por último, son los mismos artistas quienes han perdido la confianza en la capacidad del arte de significar por sí mismo, que han cedido la palabra a otro actor en esta compleja escena: el curador. 
la desarticulación misma del orden museal que en definitiva es el orden del género novela. Ricardo Piglia en Diccionario de la novela de Macedonio Fernández (2000) es categórico: "Novela equivale a museo: lugar dedicado a las musas de la Eterna. Sitio de la Inolvidable donde se vencerá el Olvido-muerte" (Piglia, 2000, p. 64) ${ }^{9}$. La novela como personaje desea resistir la muerte, fundamentalmente con el hecho de ser recordada, es decir, manteniéndose en la memoria. Los prólogos insistentes e interminables nos demuestran el interés por mantener en la memoria aquello que aun no sucede, quizá apostando a que en el momento de verbalizar la acción prologada (la novela), aquélla se instale en una línea de tiempo que, en ese mismo momento, la deja atrás, olvidada. La forma que ocupa el texto para mantener en su distancia la memoria es trayendo la atención sobre sí: se multiplica en pequeños relatos, con juegos de palabras y nos conmina a un juego en que ella asume la forma de un modelo para armar, con lo que de paso crea la novela "artística", aquella inconclusa, disonante, desordenada en que el interés por la fábula (propio de la "novela mala") es desestimado a favor del montaje o de la construcción del museo imaginario personal.

Los textos de Cristina Peri Rossi, en cambio, apuntan a otra zona de este mapa sin trama de paralelos y meridianos. La escritora uruguaya ha declarado (Golano, 1982) que su escritura se basa en el trabajo con tres símbolos importantes, el museo, el mar y el viaje, que si bien son temas transversales en su escritura, podemos reconocer con mayor intensidad en unos u otros textos. En el tema que nos ocupa podemos mencionar los libros de relatos: Los museos abandonados (1968) y El museo de los esfuerzos inútiles (1983). En ellos se nos presentan episódicamente cada uno de los relatos como cuadros plásticos (reproducciones), una especie de colección casi fetiche de personajes y ciudades artificiales, al nivel de reconocerlos pero sobresignificados y revestidos de cierto espesor plástico que se articula perfectamente con otras dimensiones del hombre contemporáneo. Dicho de otro modo, el trabajo sistemático sobre el tópico "museo" pensado como un refugio falso (Noguerol, 1995) en Los museos abandonados, pasando por el museo que es necesario destruir en El libro de mis primos (1969), hasta el museo como

\footnotetext{
${ }^{9}$ Michel Foucault añadirá en Vigilar y castigar: "El individuo es sin duda el átomo ficticio de una representación ideológica de la sociedad; pero es también una realidad fabricada por esa tecnología específica de poder que se llama la 'disciplina'. Hay que cesar de describir siempre los efectos de poder en términos negativos: 'excluye', 'reprime', 'rechaza', 'censura', 'abstrae', 'disimula', 'oculta'. De hecho, el poder produce; produce realidad; produce ámbitos de objetos y rituales de verdad. El individuo y el conocimiento que de él se puede obtener corresponden a esta producción" (2004, p. 198).
}



$55 \quad$\begin{tabular}{|r} 
Atenea 515 \\
I Sem. 2017
\end{tabular} 




receptáculo del fracaso y la frustración de aquellos seres cuyos productos transmiten la implacable alienación provocada por los filamentos invisibles del poder en El museo de los esfuerzos inútiles (1983), van tramando una obra profundamente consciente del trabajo con archivos memoriales exhibidos en un contexto museal que pone en relevancia ese "Contra-qué al que se dirige lo digno de ser conservado" (Luhmann, 2005, p. 219).

El museo de los esfuerzos inútiles parodia la idea de museo como receptáculo sagrado (templo) conservador de grandes e influyentes obras (enunciados, archivos) para dedicarse a curatoriar (seleccionar, montar, componer, conservar, etc.) una colección de proyectos a medio concluir, es decir, se pone en evidencia, se exhiben los fracasos y derrotas cuya dignidad propicia escogerlos como paradigmáticos para el futuro. El absurdo proyectado (Noguerol, 1995) en los treinta relatos del texto manifiesta la desesperanza y frustración del hombre atrapado por fuerzas invisibles (políticas, convencionalismos sociales, la rutina, etc.), situación de agobio que podemos comprender en un doble sentido: atrapados o antologados como seres de feria por su carácter excéntrico o diferente de la norma; y atrapados por su capacidad perturbadora del orden. Cecilia Lawless en "El cuerpo postmoderno en tres cuentos de Peri Rossi" (1995) concluye: "El museo funciona como una parábola de la desarticulación o fragmentación de la memoria en la ciudad moderna latinoamericana... Así las salas de museo, las exhibiciones, los letreros de identificación, obligan a la fragmentación de la historia en unidades alegóricas hechas de residuos del pasado. Sin embargo, los cuentos de Peri Rossi exigen que miremos precisamente más allá de estos residuos" (Lawless, 1995, pp. 69-70).

Así como la escritura de Peri Rossi consolida museos inútiles, José Donoso en Naturaleza muerta con cachimba (1990) despliega su sapiencia respecto del mundo del arte que nos permite reconocer de qué manera la práctica museal resignifica no sólo los objetos que se incorporan dentro de sus límites, sino también los enunciados, los discursos y las prácticas artísticas. Marcos Ruiz Gallardo cae en la seducción propia de los objetos sancionados como obras de arte, parafraseando a Aurora León en El museo. Teoría, praxis y utopía (2010) cae en "esa obstinada tendencia del hombre a venerar de forma institucionalizada y ritual los objetos que rodean nuestra existencia" (p. 9). El personaje comienza, entonces, un desplazamiento desde la ignorancia a un conocimiento falaz del mundo del arte, en que el descubrimiento por azar del Museo Larco lo introduce también, sin saberlo, en una sistemática reflexión sobre el valor de la colección de un pintor desconocido y la influencia que este "encierro parisino" tiene sobre sus actos y los 
de la Corporación para la defensa del patrimonio cultural que él dirige. Con su ingreso al mausoleo y con su inserción en el mundo curatorial, la figura de "Marcos" (límites materiales del relato plástico y constituyente del mismo) comienza a cobrar sentido y su imagen aletargada, ignorante y poca cosa empieza a quedar atrás en la medida en que cambia de velocidad, se entrega o ingresa a la práctica discursiva del mundo del arte, actividad que lo va inscribiendo rápidamente en lugares de superioridad. Los tres déjà $v u$ que sufre Marcos en el museo Larco tienen una especial significación en el relato, puesto que gatillan la notable transformación del personaje, desde un ignorante y tradicional gestor cultural a un gallardo y progresista crítico de arte, desde su cara de "gato empachado con ese bigotito ridículo" (Donoso, 1990, p. 155) a un célebre curador y protector del legado de un artista tan singular como desconocido. Es de tal magnitud esta transformación que él y su amante abandonan su humanidad y se convierten en elementos contextuales dentro de un plano distinto al de la realidad de la ficción. En otras palabras los personajes se incorporan al relato plástico como un elemento más, como un elemento transplantado (Donoso, 1990, p. 151).

Marcos Ruiz Gallardo y sus déjà vu se articulan a partir de esa cualidad original de la actividad museal: "la idea que cada persona se forja del museo responde a la conexión entre sus juicios y experiencias" (León, 2010, p. 326). Al entrar por primera vez en el museo Larco sufre "un inexplicable "déjà $v u$ "-locución que desconocería si mi acercamiento al universo de Larco que empezó en esa visita- me envolvió al entrar al museo" (Donoso, 1990, pp. 114-115). Esta experiencia de sentir que una situación X ya ha sucedido antes prefigura en la novela el fundido del plano real y el plano de la ficción plástica, de manera que no reconoce dónde se produce la paramnesia "antes de darme cuenta de si el "déjà vu" que continuaba alucinándome se situaba adentro o afuera de los cuadros" (Donoso, 1990, p. 115). A partir de esta experiencia comienza a percibir inclinación por esas escenas memoriales, por lo pronto particulares, debido a que el afecto por la memoria denota el interés por poner en valor aquella dimensión patrimonial, de índole colectiva, que privilegia la detención y resistencia a los poderes articuladores del olvido. ¿Hasta qué punto el arte o la experiencia del arte puede cambiarnos o trastornarnos? Marcos al pagar la entrada al museo busca detener el tiempo y evadir la realidad con el objeto de que Hilda olvide que quiere regresar a Santiago; sin embargo, es él quien termina olvidando el deseo que siente por su novia luego de conocer "Naturaleza muerta con cachimba", cuadro que lo estremece y que anhela poseer. 


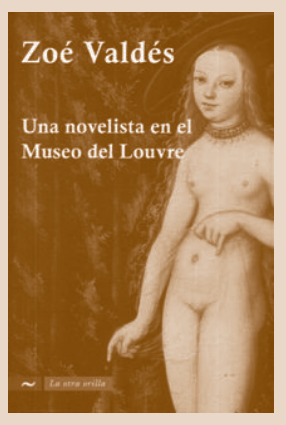

En otra zona de desarrollo, Una novelista en el Museo del Louvre (2009) de Zoé Valdés rompe con la dimensión estática del museo que congela, santifica y colecciona obras para, en un trabajo delicado y violento a la vez, otorgarles movimiento y vida, actividad que la consagra como una "fábrica de visibilidad" (Debray, 2001, p. 93). Los personajes de cuadros emblemáticos del Louvre salen de su cárcel de paspartú para movilizarse, dialogar e interactuar con aquellos otros sujetos también encerrados en la tela y que desfilan frente a una mujer, una novelista que descubre otra dimensión del museo, el reverso de aquella tradicional visión estática y contemplativa. El museo dinámico al que se refería Alfonso Reyes se instala a través de la experiencia de la novelista -quien selecciona el material de archivo (los enunciados según Foucault) - que transita por aquel museo fantasmal que adviene por momentos museo-circo o museo-zoológico debido al carácter que van asumiendo los cuadros y sus relatos, los archivos y sus pruebas, la memoria y su perdurabilidad.

El texto fabula el encuentro de dos dimensiones cuya rigidez imposibilita el acceso productivo al diálogo y la interacción entre colecciones y sus espectadores, quienes hemos ingresado al mundo del arte desde relatos mediatizados sobre autores y obras y no necesariamente desde la experiencia somática con aquellas celebridades plásticas. La novela de Valdés reviste esta problemática a partir del síndrome de Stendhal (o síndrome del viajero) sufrido por la letrada protagonista del texto embelezada por la belleza de los mitificados lienzos y esculturas a su disposición.

El encuentro, la salida de los personajes de los lienzos y la interacción desplegada en los pasillos del museo derriban en principio los límites entre arte y vida, ficción y realidad, pictura y poiesis, entre obra y espectador privilegiando ahora un relato distinto al de los catálogos de obra, en que los mismos personajes comienzan a generar alianzas, reconocimientos, cercanías y distancias con sus vecinos de pared. La escritora cubana, alter ego de su personaje, se siente deslumbrada por la experiencia extraordinaria que vive, pareciera bajo el influjo del efecto Stendhal que quisiera traspasar a los lectores. El relato nos satura de información, nombres de obras, de autores, fechas, personajes, etc., flujo discursivo desatado que evidencia el estremecimiento frente al estímulo de la belleza cifrada en los cuadros. Veinticinco son los relatos, y 126 los cuadros aludidos en 181 páginas, que dan cuenta de una dimensión alterna de las historias que cada lienzo encierra y que se nos han contado desde la expertiz de curador de turno ${ }^{10}$. Que la Mona Lisa sea una de las obras más importantes de la historia del arte tal vez no sea 
un dato relevante, lo sabemos desde este lado; pero que un personaje como Juan el Bautista salga de su cuadro con el único interés de conocer a la Gioconda pone el énfasis en el lado de allá, tal vez un espacio también contaminado por las líneas curatoriales del mundo de los vivos y de los poderosos.

Terminado este recorrido por algunos museos de papel, no nos queda más que reiterar que una investigación como la propuesta aquí sistematiza varias líneas de acceso al diálogo entre museo y novela (espacio museal y espacio literario), a la vez que proyecta zonas de reflexión interdisciplinaria y una revisión perspectivizada de este espacio memorial que instala intervenciones mayores en la conformación de colecciones que sostengan aquello notable al porvenir.

Por último, no quisiéramos pedir disculpas por tener que hablar de pintura -como diría Valery-, sino por insistir en investigar, leer y escribir de tal manera que podamos distinguir aquel destino que comparten el museo y la literatura, ese "destino ético-político, cívico" (Déotte, 1998, p. 100).

\section{REFERENCIAS}

Aumont, J. (2001). La estética hoy. Madrid: Cátedra.

Belda Navarro, C. y Marín Torres, M. (eds.). (2002). Quince miradas sobre los museos. Murcia: Universidad de Murcia y Fundación Cajamurcia.

Binni, L. y Pinna, G. (1989). Museo. Storia e funzioni di una macchina culturale dal cinquecento a oggi, profilo storico, elementi di museologia, documenti, bibliografie. Milano: Grazanti Editore.

\footnotetext{
${ }^{10} \mathrm{El}$ poder del curador comienza a hacerse manifiesto. Es este último el que construye un discurso a expensas de la obra, ejercicio en el cual se desplaza "lo artístico" desde la materialidad de la obra a su argumentación discursiva, al archivo, a los enunciados. El trabajo curatorial con archivos y su montaje particular se materializa en el acto de narrar, con Andrea Pagni, en Memoria, duelo y narración. Chile después de Pinochet: Literatura, cine, sociedad: "La memoria colectiva se configura en el acto de narrar, que es un modo de volver público el recuerdo individual y ponerlo a dialogar con otros recuerdos en una elaboración colectiva del duelo por una experiencia colectiva perdida" (2004, p. 34). Pensar el museo desde la literatura nos permite, entonces, relativizar los criterios de autoridad de aquellas instituciones que se han instalado como organismos republicanos sostenedores de un proyecto de nación, como la gran institución del quehacer cultural (Lopes, 2010) a la vez que comprender el ejercicio curatorial de archivos constructores de memoria. Lucy Lippard en Seis años: la desmaterialización del objeto artístico de 1966 a 1972 problematiza esta dimensión del fenómeno cuando apunta: "Si todo eso es confuso, considérese lo siguiente. Un conservador de museo ¿es un artista por el hecho de que emplea un grupo de pinturas y esculturas en una exposición temática para demostrar algo él mismo?” (2004, pp. 271 y ss.).
} 
Blom, P. (2013). El coleccionista apasionado. Una historia intima. Barcelona: Anagrama.

Castilla, A. (2010). El museo en escena. Política y cultura en América Latina. Buenos Aires: Paidós.

Crimp, D. (1987). On the Museum's ruins. Massachusetts: The MIT Press.

Debray, R. (2001). Introducción a la mediología. Barcelona: Paidós.

Deleuze, G. (1996). Crítica y clínica. Barcelona: Anagrama.

Déotte, J. (1998). Catástrofe y olvido. Las ruinas, Europa, el museo. Santiago: Cuarto Propio.

Derrida, J. (1997). Mal de archivo. Madrid: Trotta. (2001). "El cine y sus fantasmas". Cahiers du cinéma, № 556, web http://www.geocities.ws/patocelta/Audiovisual/Cine/cineysusfantasmDerrida.pdf

Donoso, J. (1990). Taratuta. Naturaleza muerta con cachimba. Madrid: Mondadori.

Ernst, W. (2002). Das Rumoren der Archive (El ruido de los archivos). Berlín: Merve.

Fernández, M. (2010). Museo de la novela de la Eterna: (Primera novela buena). Buenos Aires: Ed. Corregidor.

Foucault, M. (2004). Vigilar y castigar: nacimiento de la prisión. Argentina: Siglo XXI. . (2000). Arqueología del saber. Argentina: Siglo XXI.

Golano, E. (1982). "Soñar para seducir. Entrevista con Cristina Peri Rossi”. Quimera 25, 47-50.

González Echevarría, R. (2000). Mito y archivo. Una teoría de la narrativa latinoamericana. México: Fondo de Cultura Económica.

Huyssen, A. (1996). "Escapar de la amnesia. El museo como medio de masas". Revista de Crítica Cultural 13, 16-27.

Lawless, C. (1995). "El cuerpo postmoderno en tres cuentos de Peri Rossi". Cristina Peri Rossi, papeles críticos (pp. 65-79 ). Ed. Rómulo Cosse. Montevideo: Librería Linardi y Risso.

León, A. (2010). El museo. Teoría, praxis y utopía. Madrid: Cátedra.

Lippard, L. (2004). Seis años: la desmaterialización del objeto artístico de 1966 a 1972. Madrid: Akal.

Lopes, M. (2010). "Compartir espacios, colgar ballenas y apoyar a las universidades". El museo en escena. Política y cultura en América Latina. Buenos Aires: Paidós, 39-52.

Luhmann, N. (2005). El arte de la sociedad. México: Herder.

Maleuvre, D. (1999). Museum memories. History, technology, art. Stanford: Stanford University Press.

Malraux, H. (1956). Las voces del silencio. Buenos Aires: EMECÉ.

Morrison, I. (2002). "El velo pintado. La información en los museos en el siglo XXI”. Quince miradas sobre los museos (pp. 113-132). Belda Navarro, Cris- 
tóbal y Marín Torres, María Teresa (ed.). Murcia: Universidad de Murcia y Fundación Cajamurcia.

Noguerol, F. (1995). "La proyección del absurdo en El museo de los esfuerzos inútiles de Cristina Peri Rossi”. Antipodas: Journal of Hispanic Studies of Australia and New Zealand 6-7, 123-136.

Nora, P. (2009). Pierre Nora en les lieux de mémoire. Santiago: Lom.

Pagni, A. (2004). Memoria, duelo y narración. Chile después de Pinochet: literatura, cine, sociedad. Alemania: Vervuert Iberoamericana.

Pamuk, O. (2011 [2008]). El museo de la inocencia. Barcelona: De Bolsillo.

Paz, O. (2006). Corriente alterna. México D.F.: Siglo XXI.

Piglia, R. (ed.). (2000). Diccionario de la novela de Macedonio Fernández. Buenos Aires: Fondo de Cultura Económica.

Peri Rossi, C. (1974). Los museos abandonados. Barcelona: Lumen. . (1983). El museo de los esfuerzos inútiles. Barcelona: Seix Barral.

Reyes, A. (1924). Calendario. Madrid: Cuadernos literarios.

Traba, M. (1958). El museo vacío. Bogotá: Ediciones Mito.

Valdés, Z. (2009). Una novelista en el Museo del Louvre. Bogotá: Norma.

Valery, P. (1999). Piezas sobre arte. Madrid: Visor.

Virilio, P. (1997). Un paisaje de acontecimientos. Buenos Aires: Paidós.

VVAA. (2000). Lecturas de museo. Orientaciones sobre la recepción de las relaciones entre literatura y las artes. Barcelona: Publicaciones Universidad de Huelva. 